\title{
Evolution of Xylariomycetidae (Ascomycota: Sordariomycetes)
}

\author{
Samarakoon $\mathrm{MC}^{1,2,3}$, Hyde $\mathrm{KD}^{1,3^{*}}$, Promputtha $\mathrm{I}^{2}$, Hongsanan $\mathrm{S}^{\mathbf{1}}$, Ariyawansa \\ $\mathrm{HA}^{4}$, Maharachchikumbura $\mathrm{SSN}^{5}$, Daranagama $\mathrm{DA}^{1,6}$, Stadler $\mathrm{M}^{7,8}$, Mapook \\ $A^{1,3}$
}

\author{
${ }^{1}$ Center of Excellence in Fungal Research, Mae Fah Luang University, Chiang Rai 57100, Thailand \\ ${ }^{2}$ Department of Biology, Faculty of Science, Chiang Mai University, Chiang Mai 50200, Thailand \\ ${ }^{3}$ Key Laboratory for Plant Diversity and Biogeography of East Asia, Kunming Institute of Botany, Chinese Academy of \\ Sciences, 132 Lanhei Road, Kunming 650201, China \\ ${ }^{4}$ Guizhou Academy of Sciences, Guiyang, 550009, Guizhou Province, China \\ ${ }^{5}$ Department of Crop Sciences, College of Agricultural and Marine Sciences, Sultan Qaboos University, P.O. Box 34, \\ Al-Khod 123, Oman \\ ${ }^{6}$ State Key Laboratory of Mycology, Institute of Microbiology, Chinese Academy of Sciences, Beijing 100101, China \\ ${ }^{7}$ Department Microbial Drugs, Helmholtz-Zentrum für Infektionsforschung GmbH, Inhoffenstrasse 7, 38124 \\ Braunschweig, Germany \\ ${ }^{8}$ German Centre for Infection Research (DZIF), Partner Site Hannover-Braunschweig, 38124 Braunschweig, Germany
}

Samarakoon MC, Hyde KD, Promputtha I, Hongsanan S, Ariyawansa HA, Maharachchikumbura SSN, Daranagama DA, Stadler M, Mapook A. 2016 - Evolution of Xylariomycetidae (Ascomycota: Sordariomycetes). Mycosphere 7 (11), 1746-1761, Doi 10.5943/mycosphere/7/11/9

\begin{abstract}
The class Sordariomycetes, which is the second largest class in the phylum Ascomycota, comprises highly diversified fungal groups, with relatively high substitution and evolutionary rates. In this preliminary study, divergence estimates of taxa of Xylariomycetidae are calculated using Ophiocordyceps fossil evidence and secondary data. The combination of fossil and secondary calibration can affect the divergence time estimates by pushing the ages towards the roots. The estimated divergence of Hypocreomycetidae, Lulworthiomycetidae and Xylariomycetidae occurred during the Early Mesozoic (201-252 Mya) and Diaporthomycetidae and Sordariomycetidae occurred later during the Late Mesozoic (145-252 Mya). Two characteristic divergence groups have evolved 168 and 147 Mya and probably provide additional evidence for continuation and species richness of the orders Amphisphaeriales and Xylariales. The early diversifications of the families in Xylariomycetidae have occurred during the Early Cretaceous (100-145 Mya).
\end{abstract}

Key words - divergence time-fossil-paleobiology-secondary data

\section{Introduction}

Species in Sordariomycetes are endophytes, pathogens and saprobes (Zhang et al. 2006) and are characterized by perithecial ascomata, paraphyses, periphysate ostioles and unitunicate asci (Kirk et al. 2001, 2008). The species of hyphomycetes and coelomycetes linked to the Sordariomycetes have significant diversity (Zhang et al. 2006). Among the Ascomycota classes, Sordariomycetes shows a high substitution rate resulting from an acceleration of the speciation process over time, as compared to Dothideomycetes and Leotiomycetes (Wang et al. 2010). Maharachchikumbura et al. (2016) estimated there were 1,331 genera in 105 families, 32 orders 
and six subclasses in Sordariomycetes. The subclasses are Diaporthomycetidae, Hypocreomycetidae, Lulworthiomycetidae, Meliolomycetidae, Sordariomycetidae and Xylariomycetidae.

The subclass Xylariomycetidae, introduced by Eriksson \& Winka (1997), mostly comprises species with large, conspicuous stromata, although there are also numerous, less well-studied microscopic forms (Daranagama et al. 2016a). Most taxa have asci with a $\mathrm{J}+$, apical ring and brown, pigmented, unicellular ascospores, often with germ slits (Maharachchikumbura et al. 2015, Daranagama et al. 2016b). Members of Xylariomycetidae, as saprobic, pathogenic and endophytic species, have dynamic nutritional relationships with plants and animals (Zhang et al. 2006, Maharachchikumbura et al. 2016).

The subclass Xylariomycetidae were thought to comprise Amphisphaeriales and Xylariales, based on the morphological data and phylogenetic analysis of combined ITS and LSU sequence data (Smith et al. 2003, Tang et al. 2009, Senanayake et al. 2015). Senanayake et al (2015) resurrected Amphisphaeriales as a distinct order comprising the families Amphisphaeriaceae, Bartaliniaceae, Clypeosphaeriaceae, Discosiaceae (now Sporocadaceae), Pestalotiopsidaceae and Phlogicylindriaceae. The revised order Xylariales comprised the families Apiosporaceae, Cainiaceae, Coniocessiaceae, Diatrypaceae, Hyponectriaceae, Iodosphaeriaceae, Lopadostomataceae, Melogrammataceae, Pseudomassariaceae, Vialaeaceae and Xylariaceae. However, Amphisphaeriales was later considered as a synonym of Xylariales (Maharachchikumbura et al. 2016), because in the trees of Senanayake et al. (2015) there was poor statistical support for this separation. Maharachchikumbura et al. (2016) treated Xylariales with 22 well-established families, Amphisphaeriaceae, Apiosporaceae, Bartaliniaceae, Beltraniaceae, Cainiaceae, Clypeosphaeriaceae, Coniocessiaceae, Diatrypaceae, Hyponectriaceae, Iodosphaeriaceae, Lopadostomataceae, Melogrammataceae, Microdochiaceae, Myelospermataceae, Pestalotiopsidaceae, Phlogicylindriaceae, Pseudomassariaceae, Requienellaceae, Robillardaceae, Sporocadaceae (Discosiaceae), Vialaeaceae and Xylariaceae ("Hypoxyloideae" and "Xylarioideae").

However, based on the phylogenetic placement of the generic type Clypeosphaeria mamillana within the family Xylariaceae, the family Clypeosphaeriaceae has been discontinued and treated as a synonym of Xylariaceae (Jaklitsch et al. 2016). Hence Clypeosphaeria is now accepted in Xylariaceae. A new family Oxydothidaceae was introduced in Xylariomycetidae (Konta et al. 2016) based on morphological data and evidence from phylogenetic analysis of LSU, SSU and ITS sequence data. Within the family Xylariaceae there is a traditional segregation (Ju \& Rogers 1996) based on the asexual morph characters, which has been phylogenetically supported in several recent studies (Stadler et al. 2013, Daranagama et al. 2015, 2016a, b, c, Maharachchikumbura et al. 2015, 2016) as "Hypoxyloideae" and "Xylarioideae". The classifications of orders, families and genera of Xylariomycetidae however, will need further refinement when type sequences or the authentic materials are available, with focus on collections, epitypification and molecular studies (Daranagama et al. 2015, 2016a, c, Maharachchikumbura et al. 2015, 2016, Senanayake et al. 2015).

Molecular timescales can provide insights into the history of organisms, taxonomic placements and are valuable for organisms with or without fossil records ( $\mathrm{Li}$ et al. 2005, Vijaykrishna et al. 2006, Beimforde et al. 2014, Pérez-Ortega et al. 2016). Speciation events can provide valuable information concerning the genetic evolution and evolutionary history of taxon groups, through biochemical, selective pressure and population processes (Bromham \& Penny 2003). Morphological and molecular characters of fossils and living samples are also important for determining evolutionary relationships (Kemp 2005). With fossil data for the calibration of node ages, patterns of phylogenetic prediction can be determined (Taylor \& Berbee 2006). However, for the purpose of reasonable divergence time estimations, there is a need for clearly defined and dated fossils (Blair 2009).

This study focuses on the phylogenetic analyses and the application of fossil and non-fossil information for the estimation of divergence times for the subclasses within Sordariomycetes, 
specifically Xylariomycetidae. The continuation of the order Amphisphaeriales and Xylariales within the Xylariomycetidae is supported by the divergence time estimations. The diversification of Xylariomycetidae families and the provision of information for refining internal taxonomical classification are presented and described. The possibilities of using crown age dissimilarities as additional information for the differentiation of the internal groups are also discussed.

\section{Materials \& Methods}

\section{Taxon sampling, molecular data and phylogenetic analysis}

A representative set of 175 sequences from 161 species of Sordariomycetes (including 21 families belonging to the subclass Xylariomycetidae) were selected. Leotia lubrica, Coccomyces dentatus, Mollisia ventosa, M. cinerea and Thelebolus globosus from the class Leotiomycetes were selected as out group taxa. Sequence data were obtained from GenBank based on previous literature (Table 1).

Initially, multiple sequence alignments were generated from three loci (LSU, SSU and rpb2) using MAFFT v. 7 (http://mafft.cbrc.jp/alignment/server/index.html) and manually corrected where necessary using BioEdit sequence alignment editor (Hall 1999) to minimize the uninformative gaps. The final alignment consisted of 3038 characters (nuLSU-907 bp, nuSSU-1084 bp and rpb21039 bp) and gaps were treated as missing data. The substitution models for each partition were performed using Akaike Information Criterian (AIC) implemented in jMODELTEST (Darriba et al. 2012). The GTR (LSU, RPB2 - GTR+I+G) and TN93 (SSU - TrN+I+G) were used as models of substitution for phylogenetic and divergence time estimation studies. The same multiple sequence alignment was used for phylogenetic and molecular clock estimations.

Phylogenies were generated using maximum likelihood and Bayesian inference analyses. Maximum likelihood analysis was performed with RAxMLGUI v.1.3 (Silvestro \& Michalak 2012) using the ML+rapid bootstrap setting, GTRGAMMAI substitution model with 1000 replicates. The Bayesian tree was generated by using MCMC sampling in MrBayes v3.1.2 (Huelsenbeck \& Ronquist 2001, Zhaxybayeva \& Gogarten 2002) for 7000000 MCMC generations using four chains and partition analysis with 100 sample frequencies which products 14,000 trees. The first 2,800 ( $20 \%$ from total) trees were the burn-in phase and were discarded, and remaining 11,200 trees were used to calculate the posterior probability. The resulting trees were viewed with FigTree v.1.4.0 (Rambaut 2006) and the final layout was done with CorelDRAW Graphics Suite X6.

Table 1 Strains used in this study

\begin{tabular}{|c|c|c|c|c|}
\hline \multirow{2}{*}{ Species } & \multirow{2}{*}{ Culture collection no. } & \multicolumn{3}{|c|}{ GenBank Accession no. } \\
\hline & & LSU & SSU & RPB2 \\
\hline Adisciso yakushimense & HHUF 29671 & AB593721 & AB593700 & - \\
\hline Amphibambusa bambusicola & MFLUCC 11-0617 & KР744474 & - & - \\
\hline Amphisphaeria sorbi & MFLUCC 13-C0721 & KP744475 & - & - \\
\hline Amphisphaeria umbrina & HKUCC 994 & AF452029 & AY083811 & - \\
\hline Amphisphaeria umbrina & AFTOL-ID 1229 & FJ176863 & FJ176809 & - \\
\hline Annulohypoxylon multiforme & CBS 119016 & KT281893 & - & - \\
\hline Annulohypoxylon stygium & MFLUCC 12-0826 & KJ940869 & - & - \\
\hline Apiospora bambusa & ICMP 6889 & DQ368630 & DQ368662 & DQ368649 \\
\hline Apiospora setosa & ICMP 4207 & DQ368631 & DQ368661 & - \\
\hline Arecophila bambusae & HKUCC 4794 & AF452038 & AY083802 & - \\
\hline Arthrinium arundinis & AFTOL-ID 951 & DQ471018 & - & - \\
\hline Arthrinium hydei & CBS 114990 & KF144936 & - & - \\
\hline Arthrinium phaeospermum & HKUCC 3395 & AY083832 & AY083816 & - \\
\hline Ascotaiwania lignicola & NIL00005 & HQ446364 & HQ446284 & HQ446419 \\
\hline Ascotaiwania lignicola & NIL00006 & HQ446365 & HQ446285 & - \\
\hline Bartalinia robillardoides & CBS 122705 & KJ710438 & - & - \\
\hline Beltrania pseudorhombica & CBS 138003 & KJ869215 & - & - \\
\hline Beltraniella endiandrae & CBS 137976 & KJ869185 & - & - \\
\hline Beltraniopsis neolitseae & CBS 137974 & KJ869183 & - & - \\
\hline Biscogniauxia nummularia & MUCL 51395 & KT281894 & - & - \\
\hline
\end{tabular}




\begin{tabular}{|c|c|c|c|c|}
\hline \multirow{2}{*}{ Species } & \multirow{2}{*}{ Culture collection no. } & \multicolumn{3}{|c|}{ GenBank Accession no. } \\
\hline & & LSU & SSU & RPB2 \\
\hline Bombardia bombarda & AFTOL-ID 967 & DQ470970 & DQ471021 & DQ470923 \\
\hline Broomella vitalbae & MFLUCC 14-1000 & KP757750 & KP757758 & - \\
\hline Broomella vitalbae & MFLUCC 15-0023 & KP757751 & KP757759 & - \\
\hline Buergenerula spartinae & ATCC 22848 & DQ341492 & DQ341471 & - \\
\hline Cainia graminis & MFLUCC $15-0540$ & KR092781 & - & - \\
\hline Cainia graminis & CBS 136.62 & AF431949 & AF431948 & - \\
\hline Carpoligna pleurothecii & CBS 114211 & JQ429235 & JQ429249 & JQ429267 \\
\hline Chaetosphaerella fusca & GKML124N & FJ968967 & - & - \\
\hline Chaetosphaerella phaeostroma & SMH4257 & AY695264 & - & FJ968940 \\
\hline Ciferriascosea fluctamurum & MFLUCC 15-0541 & KR092778 & - & - \\
\hline Ciferriascosea rectamurum & MFLUCC $15-0542$ & KR092776 & - & - \\
\hline Ciliochorella mangiferae & MFLUCC $12-0310$ & KF827445 & KF827446 & KF827479 \\
\hline Clypeosphaeria uniceptata & HKUCC 6349 & AY083830 & AY083812 & - \\
\hline Clypeosphaeria uniseptata & HKUCC Voucher & DQ810219 & DQ810255 & - \\
\hline Coccomyces dentatus & AFTOL-ID 147 & AY544657 & AY544701 & DQ247789 \\
\hline Colletotrichum brevisporum & MFLU<THA > :LC0600 & JN940398 & JN940357 & - \\
\hline Colletotrichum fructicola & MFLU<THA >:LC0032 & JN940418 & JN940350 & - \\
\hline Colletotrichum gloeosporioides & CGMCC:LC0555 & JN940412 & JN940356 & - \\
\hline Coniocessia anandra & IRAN 1468C & GU553349 & - & - \\
\hline Coniocessia cruciformis & IRAN 1472C & GU553348 & - & - \\
\hline Coniocessia maxima & CBS 593.74 & GU553344 & - & - \\
\hline Coniocessia nodulisporioides & CBS 281.77 & GU553352 & AJ875185 & - \\
\hline Coniochaeta ligniaria & $\mathrm{C} 8$ & AY198388 & - & - \\
\hline Coniochaeta luteoviridis & CBS 206.38 & FR691987 & - & - \\
\hline Coniochaeta ostrea & AFTOL-ID 915 & DQ470959 & DQ471007 & - \\
\hline Conioscypha japonica & CBS 387.84 & AY484514 & JQ437438 & JQ429259 \\
\hline Conioscypha lignicola & CBS 335.93 & AY484513 & JQ437439 & JQ429260 \\
\hline Conioscyphascus varius & CBS 113653 & AY484512 & - & - \\
\hline Cordyceps cardinalis & OSC 93609 & AY184962 & NG013131 & - \\
\hline Cordyceps irangiensis & OSC 128578 & DQ518770 & DQ522556 & DQ522445 \\
\hline Cordyceps militaris & OSC 93623 & AY184966 & AY184977 & - \\
\hline Cosmospora coccinea & AR2741 & AY489734 & AY489702 & - \\
\hline Crassochaeta nigrita & SMH2931 & AY695266 & - & - \\
\hline Creosphaeria sassafras & ANM 1978 & JN673042 & - & - \\
\hline Creosphaeria sassafras & CM AT-018 & DQ840056 & - & - \\
\hline Cryptosphaeria ligniota & ATCC 46315 & KT425299 & - & - \\
\hline Cryptosphaeria multicontinentalis & ARG03 & KT425305 & - & - \\
\hline Cumulospora marina & MF46 & GU252135 & GU252136 & - \\
\hline Daldinia bambusicola & MFLUCC 11-0605 & KU863143 & - & KU940181 \\
\hline Daldinia concentrica & CBS 113277 & KT281895 & - & - \\
\hline Diaporthe eres & AR 3519 & AF362565 & - & - \\
\hline Diatrype disciformis & AFTOL-ID 927 & DQ470964 & DQ471012 & DQ470915 \\
\hline Diatrype palmicola & MFLUCC 11-0020 & KP744482 & KP753950 & - \\
\hline Diatrype whitmanensis & ATCC MYA-4417 & FJ430587 & FJ430578 & - \\
\hline Discosia brasiliensis & MFLUCC 12-0431 & KF827437 & KF827441 & KF827474 \\
\hline Discosia pini & MAFF 410149 & AB593708 & - & - \\
\hline Doratomyces stemonitis & AFTOL-ID 1380 & DQ836907 & DQ836901 & - \\
\hline Escovopsis weberi & ATCC 64542 & KF293281 & KF293278 & - \\
\hline Fragosphaeria purpurea & CBS 133.34 & AB189154 & AF096176 & - \\
\hline Gelasinospora tetrasperma & AFTOL-ID 1287 & DQ470980 & DQ471032 & DQ470932 \\
\hline Gliocephalotrichum bulbilium & ATCC 22228 & AY489732 & AY489700 & - \\
\hline Glomerulispora mangrovis & NBRC105264 & GU252149 & GU252150 & - \\
\hline Harknessia australiensis & CPC 15029 & JQ706211 & - & - \\
\hline Harknessia ellipsoidea & CPC 17111 & JQ706213 & - & - \\
\hline Harknessia weresubiae & CPC 17670 & JQ706244 & - & - \\
\hline Hyalotiella spartii & MFLUCC 13-0397 & KP757752 & KP757760 & - \\
\hline Hydea pygmea & NBRC 33069 & GU252133 & GU252134 & - \\
\hline Hyponectria buxi & UME 31430 & AY083834 & AF130976 & - \\
\hline Hypoxylon fragiforme & MUCL 51264 & KM186295 & - & KM186296 \\
\hline Hypoxylon lenormandii & MFLUCC 13-0311 & KM039136 & - & KM039137 \\
\hline Hypoxylon monticulosum & GZ AT-M050 & DQ840067 & - & - \\
\hline
\end{tabular}




\begin{tabular}{|c|c|c|c|c|}
\hline \multirow{2}{*}{ Species } & \multirow{2}{*}{ Culture collection no. } & \multicolumn{3}{|c|}{ GenBank Accession no. } \\
\hline & & LSU & SSU & RPB2 \\
\hline Idriella lunata & CBS 204.56 & KP858981 & - & - \\
\hline Iodosphaeria tongrenensis & GZUH0109=FJS8 & KR095283 & - & - \\
\hline Jobellisia fraterna & SMH2863 & AY346285 & - & - \\
\hline Jobellisia guangdongensis & GD14-4 & JN936990 & - & - \\
\hline Jobellisia luteola & SMH2753 & AY346286 & - & - \\
\hline Jugulospora rotula & ATCC 38359 & AY346287 & - & AY780178 \\
\hline Koralionastes ellipticus & JK5769 & EU863585 & EU863581 & - \\
\hline Koralionastes ellipticus & JK5771 & EU863583 & EU863580 & - \\
\hline Kretzschmaria deusta & CBS 163.93 & KT281896 & - & - \\
\hline Lasiosphaeria ovina & SMH4605 & AY436413 & - & AY600284 \\
\hline Leotia lubrica & AFTOL-ID 1 & NG027596 & AY544687 & DQ470876 \\
\hline Lepteutypa cupressi & IMI 052255 & AF382379 & AY083813 & - \\
\hline Lindra thalassiae & AFTOL-ID 413 & DQ470947 & DQ470994 & DQ470897 \\
\hline Lopadostoma turgidum & LT1 & KC774617 & - & KC774562 \\
\hline Lopadostoma turgidum & $\mathrm{LT}$ & KC774616 & - & KC774561 \\
\hline Lopadostoma turgidum & CBS 133207 & KC774618 & - & KC774563 \\
\hline Lulworthia fucicola & ATCC 64288 & AY878965 & AY879007 & - \\
\hline Magnaporthe poae & M47 & JF414885 & - & - \\
\hline Magnaporthe salvinii & M21=ATCC 44754 & JF414887 & - & - \\
\hline Mazzantia napelli & AR3498 = AFTOL-ID 2126 & AF408368 & DQ862051 & EU219345 \\
\hline Melanconis marginalis & AR3442 = AFTOL-ID 2128 & AF408373 & DQ862053 & EU219301 \\
\hline Melanconis stilbostoma & AR3501 = CBS 109778 & AF408374 & NG_013198 & EU219299 \\
\hline Melogramma campylosporum & MBU & JF440978 & - & - \\
\hline Microascus trigonosporus & AFTOL-ID 914 & DQ470958 & DQ471006 & - \\
\hline Microdochium bolleyi & CBS 540.92 & KP858946 & - & KP859119 \\
\hline Microdochium nivale & CBS 116205 & KP858944 & AB586893 & KP859117 \\
\hline Microdochium phragmitis & CBS 423.78 & KP858948 & - & KP859121 \\
\hline Microdochium seminicola & CBS 122707 & KP858947 & - & KP859120 \\
\hline Microdochium trichocladiopsis & CBS 623.77 & KP858934 & - & KP859107 \\
\hline Mollisia cinerea & AFTOL-ID 76 & DQ470942 & DQ470990 & DQ470883 \\
\hline Mollisia ventosa & KUS-F52181 & JN086700 & - & JN086851 \\
\hline Neonectria ramulariae & CBS 151.29 & HМ042436 & HQ840414 & DQ789792 \\
\hline Neopestalotiopsis clavispora & CBS 447.73 & KM116275 & - & - \\
\hline Neopestalotiopsis foedans & CGMCC 3.9144 & JN940832 & JN940799 & - \\
\hline Neurospora crassa & MUCL 19026 & AF286411 & X04971 & - \\
\hline Ophioceras dolichostomum & CBS 114926 & JX134689 & JX134663 & \\
\hline Ophiocordyceps gracilioides & TSJ935 & KJ130992 & - & - \\
\hline Ophiocordyceps melolonthae & TSJ679 & KJ130990 & - & - \\
\hline Ophiocordyceps sinensis & YN09-64 & JX968033 & JX968028 & JX968013 \\
\hline Ophiodiaporthe cyatheae & 1364 (HAST) & JX570891 & JX570890 & JX570893 \\
\hline Ophiostoma piliferum & AFTOL-ID 910 & DQ470955 & DQ471003 & - \\
\hline Oxydothis metroxylonicola & MFLUCC 15-0281 & KY206774 & KY206769 & KY206781 \\
\hline Oxydothis palmicola & MFLUCC 15-0806 & KY206775 & KY206771 & - \\
\hline Oxydothis rhapidicola & MFLUCC 14-0616 & KY206766 & KY206772 & - \\
\hline Parapleurotheciopsis inaequiseptata & MUCL 41089 & EU040235 & - & - \\
\hline Pestalotiopsis adusta & CGMCC 3.9103 & JN940828 & JN940796 & - \\
\hline Petriella setifera & AFTOL-ID 956 & DQ470969 & DQ471020 & - \\
\hline Phlogicylindrium eucalyptorum & CBS 111689 & KF251708 & - & - \\
\hline Phlogicylindrium eucalyptorum & CBS 111680 & KF251707 & - & - \\
\hline Phlogicylindrium uniforme & CBS 131312 & JQ044445 & - & - \\
\hline Pleurotheciella rivularia & CBS 125238 & JQ429232 & JQ429244 & JQ429263 \\
\hline Pleurothecium semifecundum & CBS 131271 & JQ429240 & JQ429254 & JQ429270 \\
\hline Podosordaria tulasnei & CBS 128.80 & KT281897 & - & - \\
\hline Pseudobeltrania ocoteae & CPC 26219 & KT950870 & - & - \\
\hline Pseudomassaria chondrospora & PC1 & JF440982 & - & - \\
\hline Pseudomassaria chondrospora & CBS 125600 & JF440981 & - & - \\
\hline Pseudomassaria sepincoliformis & CBS 129022 & JF440984 & - & - \\
\hline Pseudopestalotiopsis theae & SAJ 0021 & JN940838 & JN940785 & - \\
\hline Requienella fraxini & WU 33560 & KT949909 & - & - \\
\hline Requienella fraxini & WU 33561 & KT949910 & - & - \\
\hline Requienella fraxini & WU 33564 & КT949911 & - & - \\
\hline
\end{tabular}




\begin{tabular}{|c|c|c|c|c|}
\hline \multirow{2}{*}{ Species } & \multirow{2}{*}{ Culture collection no. } & \multicolumn{3}{|c|}{ GenBank Accession no. } \\
\hline & & LSU & SSU & RPB2 \\
\hline Requienella seminuda & WU 33568 & KT949912 & - & - \\
\hline Requienella seminuda & WU 33569 & KT949913 & - & - \\
\hline Robillarda africana & CBS 122.75 & KR873281 & - & - \\
\hline Robillarda roystoneae & CBS 115445 & KR873282 & - & - \\
\hline Robillarda sessilis & CBS 101440 & KR873283 & - & - \\
\hline Robillarda sessilis & CBS 114312 & KR873284 & - & - \\
\hline Robillarda terrae & CBS 587.71 & KJ710459 & - & - \\
\hline Rosellinia limonispora & CBS 382.86 & KF719211 & - & - \\
\hline Rosellinia necatrix & HKUCC 9037 & AY083824 & AY083805 & - \\
\hline Rostrohypoxylon terebratum & CBS 119137 & DQ840069 & - & DQ631954 \\
\hline Sarcostroma restionis & CBS 118154 & DQ278924 & - & - \\
\hline Savoryella lignicola & NF00204 & HQ446378 & HQ446300 & - \\
\hline Seimatosporium cornii & MFLUCC 14-0467 & KR559739 & KR559741 & - \\
\hline Seimatosporium lichenicola & MFLUCC 14-0052 & KT005514 & - & - \\
\hline Seiridium phylicae & CPC 19962 & NG_042759 & - & - \\
\hline Selenodriella cubensis & CBS 683.96 & KP858990 & - & - \\
\hline Selenodriella fertilis & CBS 772.83 & KP858992 & - & - \\
\hline Seynesia erumpens & SMH 1291 & AF279410 & AF279409 & AY641073 \\
\hline Sordaria fimicola & CBS 508.50 & AY681160 & - & - \\
\hline Sporothrix stenoceras & AFTOL-ID 1038 & DQ836904 & DQ836897 & - \\
\hline Subramaniomyces fusisaprophyticus & CBS 418.95 & EU040241 & - & - \\
\hline Thelebolus globosus & AFTOL-ID 5016 & FJ176905 & FJ176851 & - \\
\hline Tolypocladium capitatum & OSC 71233 & AY489721 & AY489689 & - \\
\hline Tolypocladium japonicum & OSC 110991 & DQ518761 & DQ522547 & DQ522428 \\
\hline Torpedospora ambispinosa & BCC16003 & AY858949 & AY858940 & - \\
\hline Torpedospora radiata & AFTOL-ID 751 & DQ470951 & DQ470999 & DQ470902 \\
\hline Torrubiella wallacei & CBS 101237 & AY184967 & AY184978 & EF469119 \\
\hline Trichoderma citrinoviride & CBS 258.85 & AF399228 & - & - \\
\hline Trichoderma viride & GJS89-127 & AY489726 & - & - \\
\hline Truncatella spartii & MFLUCC 15-0537 & KR092782 & - & - \\
\hline Vialaea insculpta & AFTOL-ID 1302 & KF511803 & - & - \\
\hline Vialaea mangiferae & MFLUCC $12-0808$ & KF724975 & - & - \\
\hline Vialaea minutella & BRIP 56960 & KC181925 & - & - \\
\hline Vialaea minutella & BRIP 56959 & KC181924 & - & - \\
\hline Xylaria bambusicola & MFLUCC 11-0606 & KU863148 & - & KU940183 \\
\hline Xylaria grammica & 479 (HAST) & JQ862638 & - & GQ844813 \\
\hline Xylaria hypoxylon & CBS122620 & KM186301 & - & KM186302 \\
\hline Zetiasplozna acaciae & СРC 23421 & KJ869206 & - & - \\
\hline
\end{tabular}

Fossil calibration

In this study, we selected Paleoophiocordyceps coccophagus Sung et al., a fossil from the class Sordariomycetes (Hypocreomycetidae, Hypocreales) for calibrating the tree. Sung et al. (2008) investigated a fossilized male scale (Albicoccidae) insect parasitized by $P$. coccophagus from the Late Mesozoic (Upper Albian) period in Burmese amber, which was from lignitic seams in sandstone-limestone. It is the oldest fossil evidence recorded for the fungal-animal parasitism (Sung et al. 2008). Morphological characters of the fossil P. coccophagus are similar to the asexual characters of the extant Hirsutella and Hymenostilbe (Sung et al. 2008). The genera Hirsutella and Hymenostilbe are treated as synonyms of Ophiocordyceps (Ophiocordycipitaceae, Hypocreales; Quandt et al. 2014). The age of the fossil has been calculated around 99-105 Mya based on the geological timescale (Cruickshank \& Ko 2003). Based on the geological time scale of Walker et al. (2012), the Albian period is demarcated as 100-113 Mya. In this study, the fossil data was used for the calibration of the crown node of the genus Ophiocordyceps (Exponential distribution, offset 100 , mean 27.5 , with $95 \%$ credibility interval of 182.4 Mya).

\section{Secondary calibration}

Several studies have been conducted to estimate the crown age of Sordariomycetes. According to recent studies, the estimated crown ages of the class Sordariomycetes are 256 Mya 
(202-306; Pérez-Ortega et al. 2016), 260 Mya (207-339; Beimforde et al. 2014) and 130 Mya (77181; Prieto \& Wedin 2013). The divergence time of Sordariomycetes studied by Pérez-Ortega et al. (2016) is comparatively closer to Beimforde et al. (2014). Generally, these two studies used similar fossil calibrations for the divergence time estimations (Beimforde et al. 2014, Pérez-Ortega et al. 2016). In this study, we used the mean crown age as 258 Mya (202-339) as the crown age for Sordariomycetes (normal distribution with the mean 258 and SD 35 with $95 \%$ credibility interval) of 315.6 Mya.

\section{Molecular clock analysis}

Bayesian analysis was implemented for estimation of divergence times using data from multi-gene loci and accommodating fossil and secondary calibration nodes. Two scenarios for the divergence time estimations were implemented for calibrating the tree; scenario 1 with a combination of fossil data and secondary data; scenario 2 with only secondary data. Analyses were performed using the BEAST v1.8.0. The XML file was obtained including the partitioned alignment using the BEAUti (BEAST package). The GTR (LSU, RPB2 - GTR+I+G) and TN93 (SSU $-\operatorname{TrN}+\mathrm{I}+\mathrm{G}$ ) were used as models of substitution. BEAST analyses were run for $100,000,000$ generations, logging parameters and trees were obtained for every 10,000 generations. Effective sample sizes (ESS) of parameters were checked using Tracer v.1.6 (ESS>200). A burn-in of first $30 \%$ trees was removed from each analysis based on the ESS values using Tracer v1.6 (Rambaut et al. 2013). The remaining trees were used to generate a maximum clade credibility tree by using Logcombiner v1.8.0 and TreeAnnotator v1.8.0. The resulting trees were viewed with FigTree v.1.4.0 (Rambaut 2006) and the final layout was done with CorelDRAW Graphics Suite X6.

\section{Results}

\section{Topology of the Xylariomycetidae}

The results from RAxML and Bayesian analyses using LSU, SSU and rpb2 sequence data are shown in Fig. 1. The overall topology for the higher-level relationships is quite similar to those in previous phylogenetic analyses (Maharachchikumbura et al. 2015, 2016, Senanayake et al. 2015). The subclasses Diaporthomycetidae, Hypocreomycetidae, Lulworthiomycetidae, Sordariomycetidae and Xylariomycetidae cluster in Sordariomycetes (100 ML/1 PP). Lulworthiomycetidae and Hypocreomycetidae are sister clades (52 ML) as basal to the sister clade comprising Diaporthomycetidae, Sordariomycetidae and Xylariomycetidae. Diaporthomycetidae and Sordariomycetidae are sister clades (81 ML/0.99 PP) as basal to Xylariomycetidae. The 22 families of Xylariomycetidae clustered together (73 ML/0.98 PP). The subclass Meliolomycetidae is, however, not included in this study.

The family Iodosphaeriaceae diverges as a basal clade from other families of Xylariomycetidae. Microdochiaceae and Coniocessiaceae are sister families (88 ML/1 PP), forming a basal clade to other families. The families Amphisphaeriaceae, Apiosporaceae, Bartaliniaceae, Beltraniaceae, Hyponectriaceae, Melogrammataceae, Oxydothidaceae, Pestalotiopsidaceae, Phlogicylindriaceae, Pseudomassariaceae, Robillardaceae, Sporocadaceae and Vialaeaceae (Clade I, possible Amphisphaeriales), cluster sister to the families Cainiaceae, Diatrypaceae, Lopadostomataceae, Requinellaceae and Xylariaceae ("Hypoxyloideae" and "Xylarioideae"; as Clade II, possibly Xylariales sensu stricto).

\section{Divergence time estimations with a combination of fossil and secondary calibration}

The comparable results $(95 \% \mathrm{CI})$ from both scenarios 1 and 2 are listed in the Table 2 . The divergence times estimated using a combination of fossil and secondary data (Scenario 1) are older than the divergence times estimated using only secondary data (Scenario 2). According to the estimates in Scenario 1, the class Sordariomycetes diverged from Leotiomycetes during the Paleozoic, around 343 Mya (264-446). The crown age of the class Sordariomycetes is around 300 Mya (249-359) during the Paleozoic. The subclasses Lulworthiomycetidae and Hypocreomycetidae 
diverged approximately at 284 Mya (233-342) during the Late Paleozoic, while the crown ages of these two subclasses occurred during the Early Mesozoic; Lulworthiomycetidae 216 Mya (150284), Hypocreomycetidae 245 Mya (199-301). The crown age of the clade comprising Sordariomycetidae, Diaporthomycetidae and Xylariomycetidae is around 274 Mya (216-337) during the Late Paleozoic and 228 Mya (169-290) for the split between Diaporthomycetidae and Sordariomycetidae during the Early Mesozoic. The earliest splits (crown ages) of the Sordariomycetidae (179 Mya), Diaporthomycetidae (197 Mya) and Xylariomycetidae (219 Mya) occurred during the Mesozoic. The crown age of the fossil in Hypocreales is around 163 Mya (129200) with the stem age around 200 Mya (158-248) during the Middle of Mesozoic. The crown node ages of the families Microdochiaceae and Xylariaceae belong to the Late Mesozoic (66-100 Mya), while the majority of the families have diversified during the Cenozoic (66 Mya to present; see Fig 2). Divergence times of other families in Xylariomycetidae are shown in Fig. 2.

Table 2 Comparison of the estimated divergence times (Mya) with $95 \%$ credibility intervals (CI) for Scenarios 1 and 2.

\begin{tabular}{clcc}
\hline \multirow{2}{*}{ Node } & \multicolumn{1}{c}{ Node age } & \multicolumn{2}{c}{ Age (95\% CI) Mya } \\
\cline { 3 - 4 } & & $347(267-456)$ & Scenario 1 \\
\hline 1 & Leotiomycetes-Sordariomycetes & $308(254-364)$ & $243(182-369)$ \\
2 & Sordariomycetes crown group & $291(237-348)$ & $227(159-294)$ \\
3 & Lulworthiomycetidae-Hypocreomycetidae & $219(150-286)$ & $164(94-236)$ \\
4 & Lulworthiomycetidae crown group & $252(200-305)$ & $186(125-250)$ \\
5 & Hypocreomycetidae crown group & $282(221-340)$ & $218(147-287)$ \\
6 & Sordariomycetidae - Diaporthomycetidae-Xylariomycetidae & $236(172-298)$ & $178(113-244)$ \\
7 & Diaporthomycetidae-Sordariomycetidae & $182(121-251)$ & $136(70-199)$ \\
8 & Sordariomycetidae crown group & $203(141-266)$ & $153(94-214)$ \\
9 & Diaporthomycetidae crown group & $235(172-298)$ & $173(113-243)$ \\
10 & Xylariomycetidae crown group & $147(103-199)$ & $104(66-152)$ \\
11 & Amphisphaeriales crown group & $168(122-219)$ & $119(77-167)$ \\
12 & Xylariales crown group & & \\
\hline
\end{tabular}

\section{Discussion}

\section{Assigning calibration points}

The Paleoophiocordyceps coccophagushas fossil appears to be similar to Hirsutella and Hymenostilbe species, which are now considered as the asexual morphs of Ophiocordyceps (Sung et al. 2008, Quandt et al. 2014). This provides additional evidence for the fossil calibration in the molecular clock analyses. The internal node calibration emphasizes the relationships among taxa (Ho \& Phillips 2009). The fossil representing Hypocreomycetidae might provide acceptable divergence time estimates for taxa within Sordariomycetes. The known divergence dates from fossils (Mitchell-Olds \& Bergelson 2000) and the availability of acceptable external calibration points (Lücking et al. 2009), can be used to estimate the divergence times. However, a combination of geological and molecular information, with appropriate selection of methods, with more representative fossil data, can provide reasonable lower (lower boundary) divergence times, but rarely realistic upper boundary of divergence times (Guicking et al. 2006, Eme et al. 2014, Magallón et al. 2015). The use of multiple calibration points can result in more comprehensive estimates than a single calibration point (Ho \& Phillips 2009). Thus, the use of previous results as secondary calibrations (Beimforde et al. 2014, Pérez-Ortega et al. 2016), with an internal fossil, provides reasonable estimates; in addition, it avoids repetition of estimates. Hug \& Roger (2007) suggested that the accumulation of the error in the original study might be a problem when using only secondary information. 


\section{The impact of calibrations}

In most of the cases, the paleontological time estimations deviate from the molecular estimations (Hug \& Roger 2007). This can result from model selection, sequence data and the

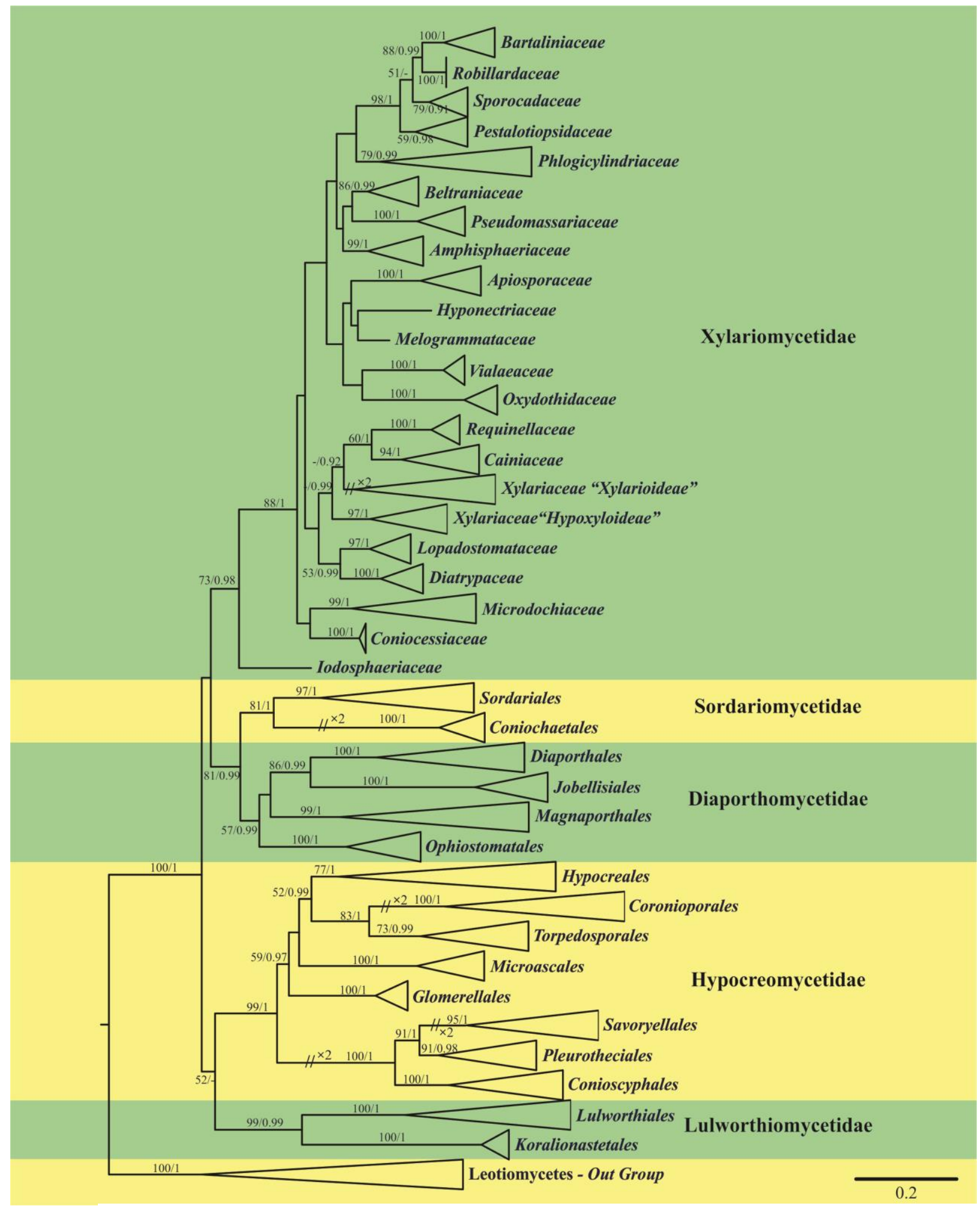

Fig. 1 - Consensus tree resulting from a maximum likelihood analysis (compressed over view) of a combined LSU, SSU and RPB2 sequence alignment for taxa of Xylariomycetidae and other selected isolates of Sordariomycetes. RAxML bootstrap support values (ML above 50) and Bayesian posterior probabilities (PP above 0.9) are given at the nodes (ML/PP). The scale bar represents the expected number of changes per site. The tree is rooted to Leotia lubrica, Coccomyces dentatus, Mollisia ventosa, M. cinerea and Thelebolus globosus. 


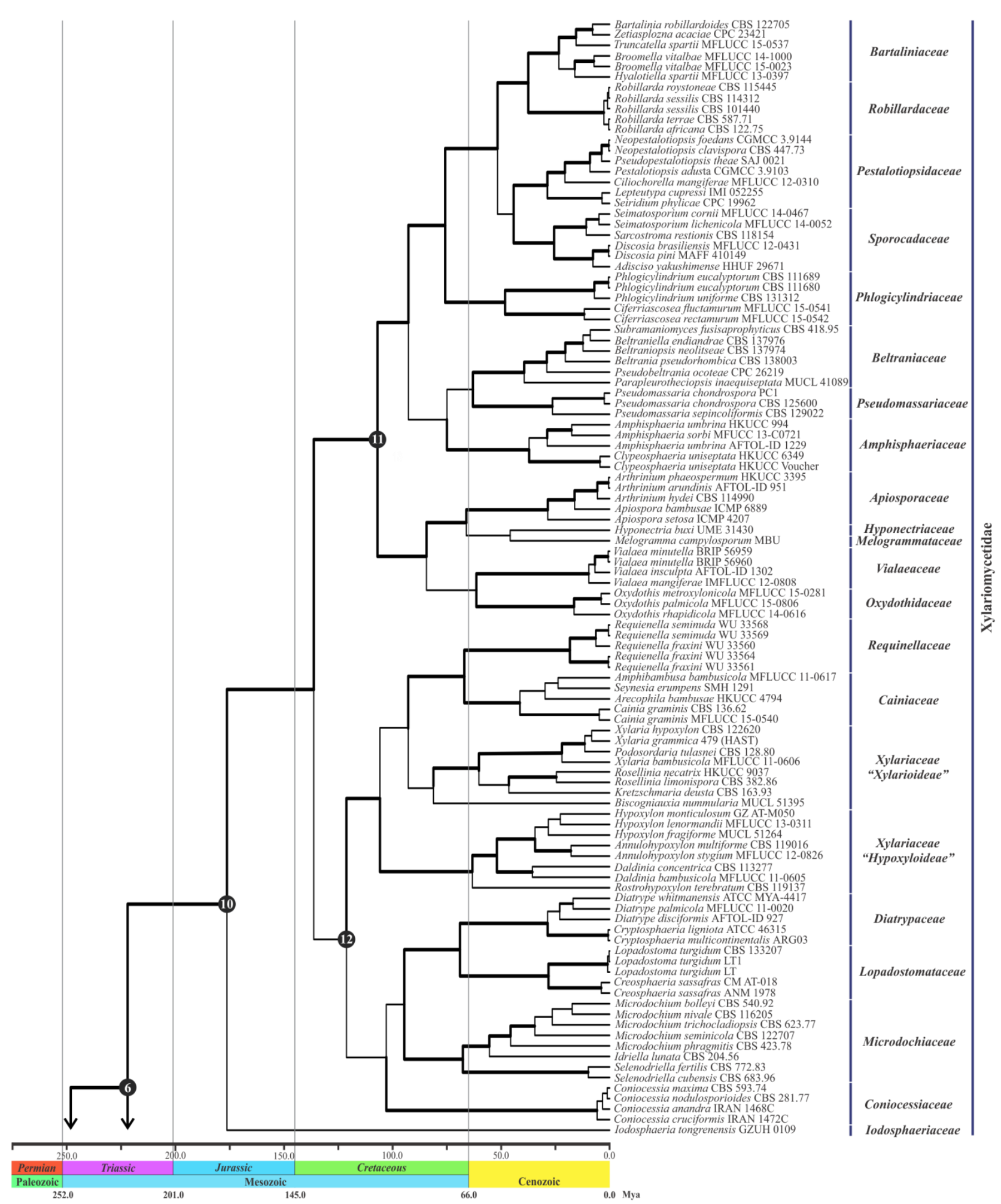

Fig. 2 - Xylariomycetidae divergence time tree (Scenario 2) estimated using lognormal relaxed clock mode (uncorrelated) in BEAST, with representative families. Numbers in the black circles indicate the median age and 95\% highest posterior density (HPD) from Table 2 . The yellow and red circles indicate the fossil (Scenario 1) and secondary (Scenarios 1 and 2) points respectively. Branches $>0.9 \mathrm{PP}$ are in bold. 


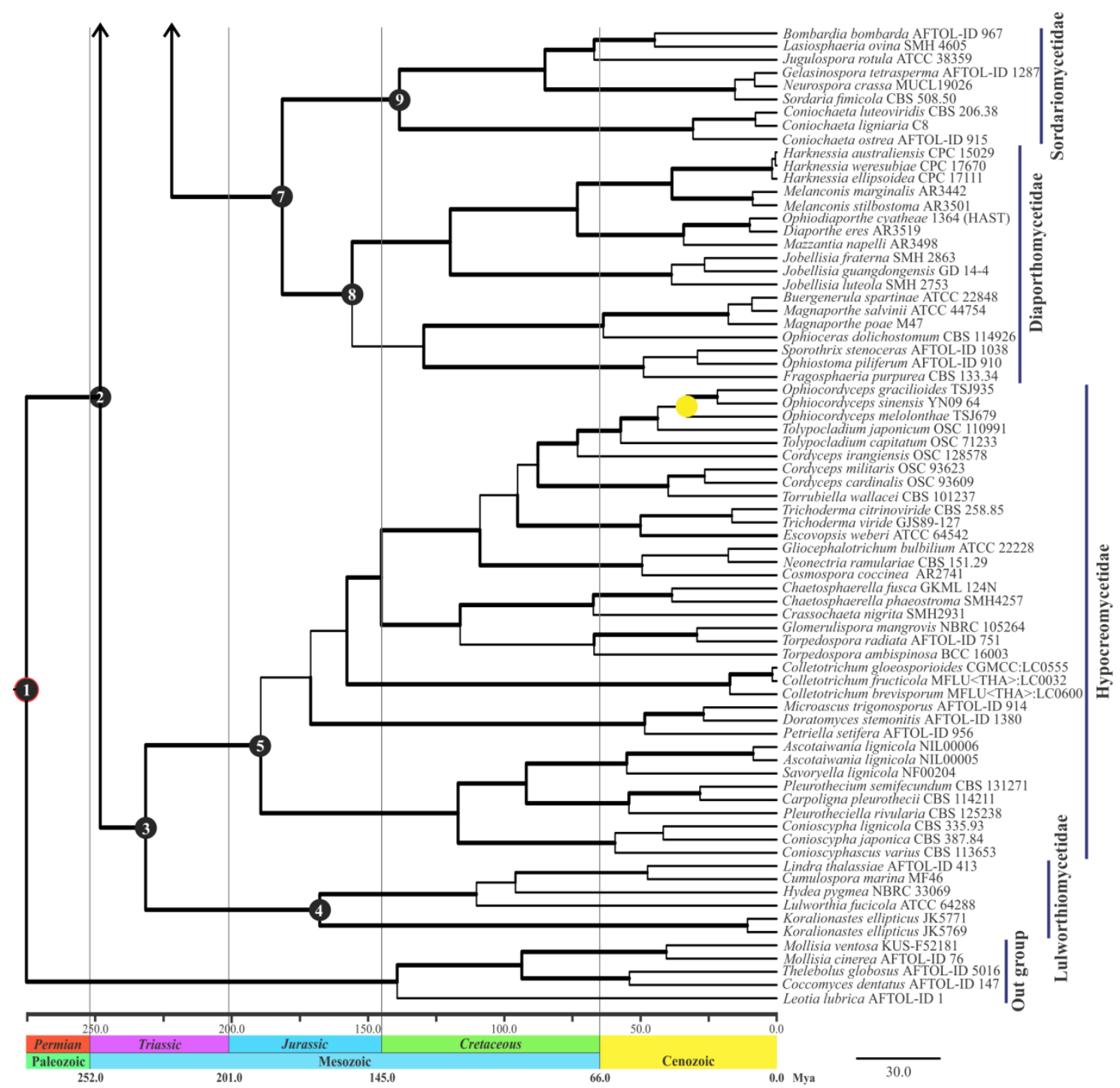

Fig. 2 - continued

calibration points (Hug \& Roger 2007). Our sequence data set comprise a large number of species of Xylariomycetidae and Hypocreomycetidae. However, Hug \& Roger (2007) suggested that the taxon sampling of the data set is less important for the age estimation. In addition, the use of single fossil for the calibration leads to unpredictable results (Hug \& Roger 2007).

The estimated crown ages of Hypocreales are 167 Mya (Scenario 1) and 106 Mya (Scenario 2). Sung et al. (2008) estimated that the crown age of the Hypocreales as 193 Mya using the Paleoophiocordyceps coccophagushas fossil. Our results from Scenario 1 are similar to Sung et al. (2008). In this study, the combination of fossil and estimated mean divergence times as secondary information (Scenario 1) resulted in older divergence times, as compared to the secondary information alone (Scenario 2). In the first scenario, the fossil calibration might push the divergence times towards the bases. In the second scenario, there is no effect from terminal nodes to the bases. Because of the uncertainty of the estimated divergence times when using only secondary data for the calibration (Hug \& Roger 2007) and the earlier divergence times of extant species, the results from Scenario 1 are considered more accurate and are discussed further.

\section{Evolution of major groups}

The divergences of the subclasses in Sordariomycetes are discussed in this section based on the combined calibrations in Scenario 1 (see Table 2 and Fig. 2). The major clades are wellsupported in both phylogenies and the divergence times, largely overlapping with previous studies (Beimforde et al. 2014, Pérez-Ortega et al. 2016). The Paleozoic divergence of Leotiomycetes and 
Sordariomycetes in our study (347 Mya), is similar to those in recent studies (317 Mya in PérezOrtega et al. 2016 and 309 Mya in Beimforde et al. 2014). Prieto \& Wedin (2013) however gave a younger estimated age for the split between Leotiomycetes and Sordariomycetes at 247 Mya, during the Early Mesozoic. The Devonian to Late Paleozoic (290-380 Mya, Lücking et al. 2009), Permian 256 Mya (202-306, Pérez-Ortega et al. 2016) and 260 Mya (207-339, Beimforde et al. 2014) and Early Mesozoic 229 Mya (Gueidan et al. 2011) divergences of Sordariomycetes crown, have been reported in several studies. We also provide a reasonable age estimate for Sordariomycetes crown at 308 Mya, during the Late Paleozoic. Beimforde et al. (2014) suggested that the divergences of classes in Pezizomycotina started during the Ordovician (444-485 Mya). The classes Dothideomycetes and Sordariomycetes comprise a highly-diversified group, with saprobic, pathogenic, endophytic, epiphytic, fungicolous, lichenized or lichenicolous life styles, and are found in terrestrial, freshwater and marine habitats (Hyde et al. 2013, Jones et al. 2015, Maharachchikumbura et al. 2016). During the Paleozoic (252-541 Mya), it is thought that highly diversified plant-fungal interactions played a crucial role as the back bone of the ecosystem (Selosse et al. 2015). The divergence of Dothideomycetes crown group (290 Mya) occurred before Sordariomycetes (256 Mya) and the former class has a higher species richness (Pérez-Ortega et al. 2016). The high species richness in the Dothideomycetes might be a result of its early divergence or that species were better adapted to a range of environments. However, the relationship between early divergence and the species richness is still unclear (Magallón et al. 2015).

The phylogenies and divergent time tree provides support for five subclasses of Sordariomycetes. The subclasses Lulworthiomycetidae, Hypocreomycetidae, and Xylariomycetidae appear to have originated during the Early Mesozoic (201-252 Mya), while Sordariomycetidae and Diaporthomycetidae originated during the Middle of Mesozoic (145-201 Mya). The subclass Meliolomycetidae was not included in this study. The Late Paleozoic-Early Mesozoic mass extinction event is thought to have occurred around 251 Mya, and therefore it has been postulated that fungal species might have rapidly dominated terrestrial ecosystems during this time (Anon 2014, Eshet et al. 1995, Schubert \& Bottjer 1995), or only shallow marine deposits (Wignall 1996), where dead biomass provided abundant organic matter for saprobes (Eschet et al. 1995). Lulworthiomycetidae (all aquatic and mostly marine), Hypocreomycetidae (mostly terrestrial, and insect fungi) and Xylariomycetidae (mostly terrestrial wood degraders) are mostly saprobes (Kirk et al. 2008, Boonyuen et al. 2011, Senanayake et al. 2015, Maharachchikumbura et al. 2015). Beimforde et al. (2014) suggested that ecological diversification of a few Ascomycota in each lineage might have protected them from mass extinction. Many species in Xylariomycetidae have large stromata and are saprobes, but there are also many microfungal representatives (Daranagama et al. 2016a).

\section{Phylogeny of Xylariomycetidae}

In the phylogenies, there is lack of statistical support for the two main clusters within Xylariomycetidae in both maximum likelihood and Bayesian analysis when using LSU, SSU and $\mathrm{rpb} 2$ sequence data. These two main clades were used as evidence for the orders Amphisphaeriales and Xylariales as morphologically they can clearly be separated (Senanayake et al. 2015). Because of the poor phylogenetic support, Amphisphaeriales was placed under Xylariales in Jaklitsch et al. (2016) and Maharachchikumbura et al. (2016). There orders however, have different divergence estimates (147 Mya in Amphisphaeriales, versus 168 Mya in Xylariales Mya (Fig. 3) in the maximum clade credibility (MCC) tree and provides evidence for at least two distinct orders. The order Amphisphaeriales comprises Amphisphaeriaceae, Apiosporaceae, Bartaliniaceae, Beltraniaceae, Hyponectriaceae, Melogrammataceae, Oxydothidaceae, Pestalotiopsidaceae, Phlogicylindriaceae, Pseudomassariaceae, Robillardaceae, Sporocadaceae and Vialaeaceae, while Xylariales comprises Cainiaceae, Coniocessiaceae, Diatrypaceae, "Hypoxyloideae", Lopadostomataceae, Microdochiaceae, Requinellaceae and "Xylarioideae The divergence of Amphisphaeriales and Xylariales are similar to the common divergence trend of most of the fungal orders reported in Samarakoon et al. (2016) at 66-252 Mya. Therefore, we recommend that based 
on the additional evidence provided here (Fig. 2), that the order Amphisphaeriales should be retained as a well-supported order.

\section{Xylariomycetidae}

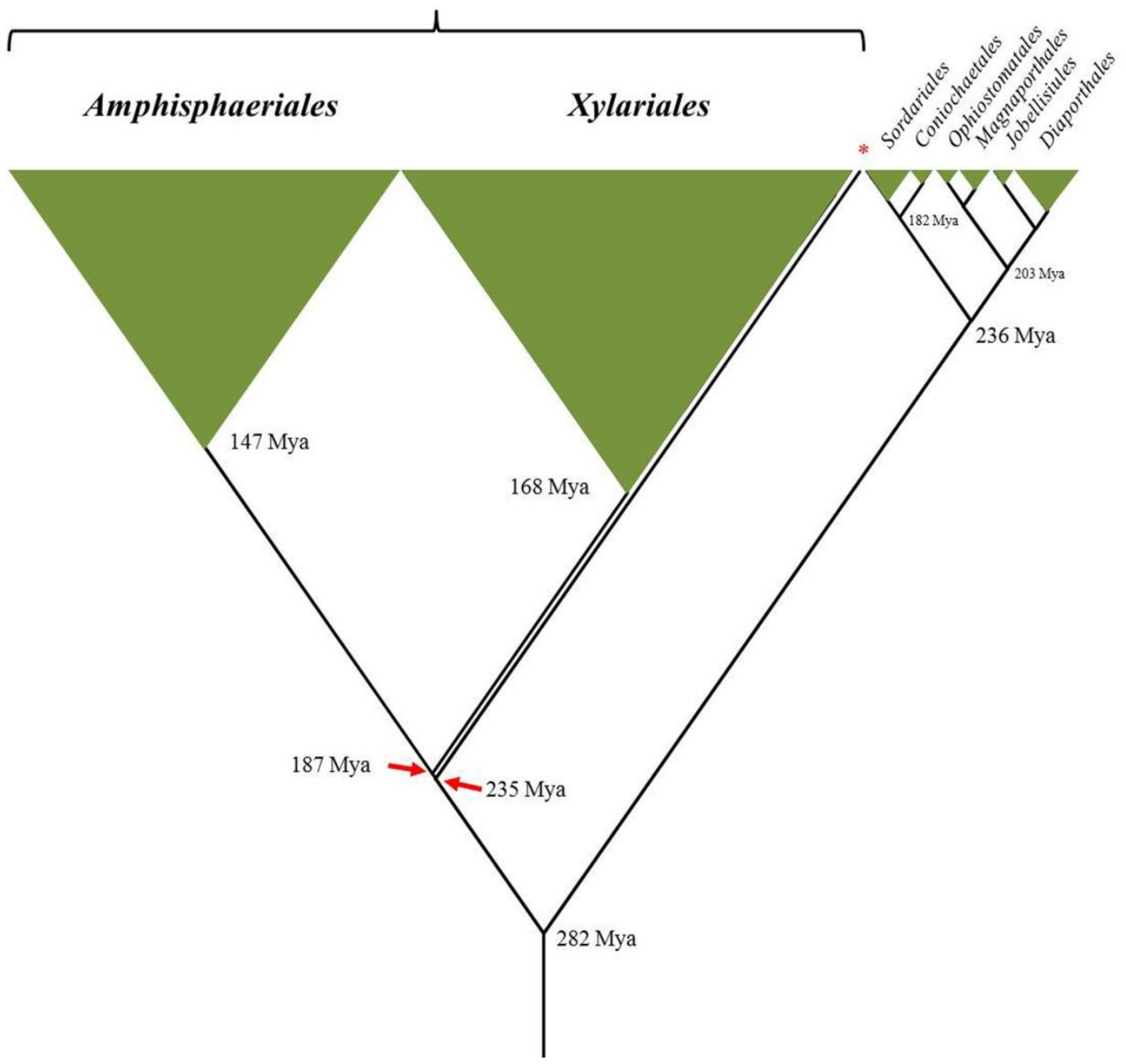

Fig. 3 - The major crown group of Xylariomycetidae (Amphisphaeriales - 147 Mya; Xylariales $168 \mathrm{Mya})$. The $*$ denotes the family Iodosphaeriaceae in the subclass Xylariomycetidae

Iodosphaeriaceae is basal to all families in Amphisphaeriales and Xylariales and diverged 235 Mya. The evidence in the divergence tree (Fig. 2) therefore suggests that this family evolved early on in the subclass and may require its own order status. The life style (probably endophytic and then saprobic on leaves), morphology with unusual hairy, superficial ascomata (Hilber \& Hilber 2002) and distinct phylogeny (Fig. 2) support this. Some other families in Amphisphaeriales and Xylariales also clustered as distinct groups. For example, Diatrype and Lopadostoma in Xylariales and Oxydothis and Vialaeaceae in Amphisphaeriales can be considered. However, the divergence estimates at 95 Mya for the split of Diatrype and Lopadostoma and 83 Mya for the split of Oxydothis and Vialaea may be too recent to warrant order status.

Most families in Xylariomycetidae originated during the Mesozoic (from 100 Mya); however, the exact crown ages are unclear due to limitations in available sequence data. Within the family Xylariaceae, there are two major clades represented by "Xylarioideae" and "Hypoxyloideae" with different stem ages (144 Mya and 127 Mya respectively). This provides additional evidence for the introduction of "Hypoxyloideae" as a new family. The phylogenetic relationships within Xylariomycetidae need further refining following the arrangements of Senanayake et al. (2015) and Maharachchikumbura et al. $(2015,2016)$. However, the lack of sequence data in most of the groups and several unresolved lineages within Xylariomycetidae that 
need to be explored (Daranagama et al. 2016a) with the combination of the phylogeny, paleobiology and ecology.

\section{Conclusion}

This is a preliminary study, for the application of divergence times on unresolved taxon groups. During the Late Paleozoic, the class Sordariomycetes became highly diversified, splitting into at least five subclasses during the Early Mesozoic and the Middle of Mesozoic. The wide range of nutritional modes and habitats in Sordariomycetes might have been advantageous for the survival and rapid domination in terrestrial, marine and freshwater habitats, even after the mass extinction that occurred during the Late Paleozoic-Early Mesozoic. The divergence age differences in the clusters of taxa in Xylariomycetidae, indicate that they diverged into numerous families of mostly saprobic taxa starting from Late Mesozoic (100 Mya).

\section{Acknowledgements}

Kevin D. Hyde thanks the Chinese Academy of Sciences, project number 2013T2S0030, for the award of Visiting Professorship for Senior International Scientists at Kunming Institute of Botany. The authors extend gratitude to Dr. Martin Ryberg, Department of Organismal Biology, Evolutionary Biology Centre, Uppsala University, SE 75236 Uppsala, Sweden for his valuable comments and advice on this manuscript.

\section{References}

Anon. 2014 - Mass extinction. [Online].[Accessed on 28.10.2016] available at http://www.newworldencyclopedia.org/entry/Mass_extinction.

Beimforde C, Feldberg K, Nylinder S, Rikkinen J et al. 2014 - Estimating the Phanerozoic history of the Ascomycota lineages: Combining fossil and molecular data. Molecular Phylogenetics \& Evolution 78, 386-398.

Blair JE. 2009 - Fungi. In: Hedges SB, Kumar S., ed. The Timetree of life. Oxford University Press, New York. p. 215-219.

Boonyuen N, Chuaseeharonnachai C, Suetrong S, Sri-indrasutdhi V et al. 2011 - Savoryellales (Hypocreomycetidae, Sordariomycetes): a novel lineage of aquatic ascomycetes inferred from multiple-gene phylogenies of the genera Ascotaiwania, Ascothailandia, and Savoryella. Mycologia, 103, 1351-1371.

Bromham L, Penny D. 2003 - The modern molecular clock. Nature Review (Genetics) 4, 216-224.

Cruickshank RD, Ko K. 2003 - Geology of an amber locality in the Hukawng Valley, Northern Myanmar. Journal of Asian Earth Sciences 21, 441-455.

Daranagama DA, Camporesi E, Tian Q, Liu X, Chamyuang S, Stadler M, Hyde KD. 2015 Anthostomella is polyphyletic comprising several genera in Xylariaceae. Fungal Diversity 73, 203-238.

Daranagama DA, Jones EBG, Liu XZ, To-anun C et al. 2016a - Mycosphere Essays 13 - Do xylariaceous macromycetes make up most of the Xylariomycetidae? Mycosphere 7, 582601.

Daranagama DA, Camporesi E, Liu XZ, Bhat DJ et al. 2016b - Tristratiperidium microsporum gen. et sp. nov. (Xylariales) on dead leaves of Arundo plinii. Mycological progress 15, 1-8

Daranagama DA, Camporesi E, Liu XZ, Jeewon R et al. 2016c - Taxonomic rearrangement of Anthostomella (Xylariaceae) based on multigene phylogenies and morphology. Cryptogamie Mycology 37, 509-538.

Darriba D, Taboada GL, Doallo R, Posada D. 2012 - jModelTest 2: more models, new heuristics and parallel computing. Nature Methods 9, 772.

Eme L, Sharpe SC, Brown MW, Roger AJ. 2014 - On the Age of Eukaryotes: Evaluating Evidence from Fossils and Molecular Clocks. Cold Spring Harbor Perspectives in Biology doi: 10.1101/cshperspect.a016139.

Eriksson OE, Winka K. 1997 - Supraordinal taxa of Ascomycota. Myconet 1, 1-16. 
Eshet Y, Rampino MR, Visscher H. 1995 - Fungal event and palynological record of ecological crisis and recovery across the Permian-Triassic boundary. Geology 23, 967-970.

Gueidan C, Ruibal C, De Hoog GS, Schneider H. 2011 - Rock-inhabiting fungi originated during periods of dry climate in the late Devonian and middle Triassic. Fungal Biology 115, 987996.

Guicking D, Lawson R, Joger U, Wink M. 2006 - Evolution and phylogeny of the genus Natrix (Serpentes: Colubridae). Biological Journal of the Linnean Society 87, 127-143.

Hall TA. 1999 - BioEdit: a user-friendly biological sequence alignment editor and analysis program for Windows 95/98/NT. Nucleic Acids Symposium Series 41, 95-98.

Hilber R, Hilber O. 2002 - The genus Lasiosphaeria and allied taxa. Hilber, 1-9.

Ho SYW, Phillips MJ. 2009 - Accounting for Calibration Uncertainty in Phylogenetic Estimation of Evolutionary Divergence Times. Systematic Biology, syp035.

Huelsenbeck, JP, Ronquist F. 2001 - MRBAYES: Bayesian inference of phylogenetic trees. Bioinformatics 17(8), 754-755.

Hug LA, Roger AJ. 2007 - The impact of fossils and taxon sampling on ancient molecular dating analyses. Molecular Biology \& Evolution 24, 1889-1897.

Hyde KD, Jones EBG, Liu JK, Ariyawansa H et al. 2013 - Families of Dothideomycetes. Fungal Diversity 63, 1-313.

Jaklitsch WM, Gardiennet A, Voglmayr H. 2016 - Resolution of morphology-based taxonomic delusions: Acrocordiella, Basiseptospora, Blogiascospora, Clypeosphaeria, Hymenopleella, Lepteutypa, Pseudapiospora, Requienella, Seiridium and Strickeria. Persoonia 37, 82 -105.

Jones EBG, Suetrong S, Sakayaroj J, Bahkali AH et al. 2015 - Classification of marine Ascomycota, Basidiomycota, Blastocladiomycota and Chytridiomycota. Fungal Diversity 73, $1-72$.

Ju YM, Rogers JD. 1996 - A revision of the genus Hypoxylon. Mycologia Memoir No. 20. APS Press, St. Paul, 365.

Konta S, Hongsanan S, Tibpromma S, Thongbai B et al. 2106 - An advance in the endophyte story: Oxydothidaceae fam. nov. with six new species of Oxydothis. Mycosphere 7, 1416-1436, doi:10.5943/mycosphere/7/9/15.

Kemp TS. 2005 - The Origin and Evolution of Mammals. Oxford University Press Inc., New York.

Kirk PM, Cannon PF, David JC, Stalpers JA. 2001 - Ainsworth \& Bisby's Dictionary of the fungi, $9^{\text {th }}$ edn. CAB international, Wallingford, UK.

Kirk PM, Cannon, PF, Minter DW, Stalpers JA. 2008 - Ainsworth \& Bisby's dictionary of the fungi, $10^{\text {th }}$ edn. CAB International, Wallingford, UK.

Li Y, Hyde KD, Jeewon R, Cai L, Vijaykrishna D, Zhang K. 2005 - Phylogenetics and evolution of nematode-trapping fungi (Orbiliales) estimated from nuclear and protein coding genes. Mycologia 97, 1034-1046.

Lücking R, Huhndorf S, Pfister DH, Plata ER, Lumbsch HT. 2009 - Fungi evolved right on track. Mycologia 101, 810-822.

Magallón S, Gómez-Acevedo S, Sánchez-Reyes LL, Hernández-Hernández T. 2015 - A metacalibrated time-tree documents the early rise of flowering plant phylogenetic diversity. New Phytologist 207, 437-453.

Maharachchikumbura SSN, Hyde KD, Jones EBG, McKenzie EHC et al. 2015 - Towards a natural classification and backbone tree for Sordariomycetes. Fungal Diversity 72, 199-301.

Maharachchikumbura SSN, Hyde KD, Jones EBG, McKenzie EHC et al. 2016 - Families of Sordariomycetes. Fungal Diversity 79, 1-317.

Mitchell-Olds T, Bergelson J. 2000 - Biotic interactions Genomics and coevolution; Editorial overview. Current Opinion in Plant Biology 3, 273-277.

Pérez-Ortega S, Garrido-Benavent I, Grube M, Olmo R, de los Ríos A. 2016 - Hidden diversity of marine borderline lichens and a new order of fungi: Collemopsidiales (Dothideomyceta). Fungal Diversity 80, 285-300. 
Prieto M, Wedin M. 2013 - Dating the Diversification of the Major Lineages of Ascomycota (Fungi). PLoS ONE 8, e65576.

Quandt CA, Kepler RM, Gams W, Araújo JPM et al. 2014 - Phylogenetic-based nomenclatural proposals for Ophiocordycipitaceae (Hypocreales) with new combinations in Tolypocladium. IMA Fungus 5, 121-134.

Rambaut A. 2006 - FigTree. Tree figure drawing tool version 1.3.1, Institute of Evolutionary Biology, University of Edinburgh. <http://tree.bio.ed.ac.uk/software/figtree/>.

Rambaut A, Suchard MA, Xie D, Drummond AJ. 2013 - Tracer version 1.6. University of Edinburgh. [Online]. [Accessed on 19.11.2016] available at http://tree.bio.ed.ac.uk/software/tracer.

Samarakoon MC, Hyde KD, Promputtha I, Ariyawansa HA, Hongsanan S 2016 - Divergence and ranking of taxa across the kingdoms Animalia, Fungi and Plantae. Mycosphere 7, 1678-1689.

Schubert JK, Bottjer DJ. 1995 - Aftermath of the Permian-Triassic mass extinction event: Paleoecology of Lower Triassic carbonates in the western USA. Palaeogeography, Palaeoclimatology, Palaeoecology 116, 1-39.

Selosse M, Strullu-Derrien C, Martin FM, Kamoun S, Kenrick P. 2015 - Plants, fungi and oomycetes: a 400-million year affair that shapes the biosphere. New Phytologist 206, 501506.

Senanayake IC, Maharachchikumbura SSN, Hyde KD, Bhat JD et al. 2015 - Towards unraveling relationships in Xylariomycetidae (Sordariomycetes). Fungal Diversity 73, 73-144.

Silvestro D, Michalak I. 2012 - raxmlGUI: a graphical front-end for RAxML. Organisms Diversity \& Evolution 12, 335-337

Smith GJD, Liew ECY, Hyde KD 2003 - The Xylariales: a monophyletic order containing 7 families. Fungal Diversity 13, 185-218.

Stadler M, Kuhnert E, Peršoh D, Fournier J. 2013 - The Xylariaceae as model example for a unified nomenclature following the "One fungus-one name" (1F1N) concept. Mycology: An International Journal of Fungal Biology 4, 5-21.

Sung GH, Poinar Jr GO, Spatafora JW. 2008 - The oldest fossil evidence of animal parasitism by fungi supports a Cretaceous diversification of fungal-arthropod symbioses. Molecular Phylogenetics \& Evolution 49, 495-502.

Tang A, Jeewon R, Hyde K. 2009 - A re-evaluation of the evolutionary relationships within the Xylariaceae based on ribosomal and protein-coding gene sequences. Fungal Diversity 34, 127-155.

Taylor JW, Berbee ML. 2006 - Dating divergences in the Fungal Tree of Life: Review and new analyses. Mycologia 98, 838-849.

Vijaykrishna D, Jeewon R, Hyde KD 2006 - Molecular taxonomy, origins and evolution of freshwater ascomycetes. Fungal Diversity 23, 351-390.

Walker JD, Geissman JW, Bowring SA, Babcock LE. 2012 - Geologic Time Scale v. 4.0: Geological Society of America doi: 10.1130/2012.CTS004R3C.

Wang HY, Guo SY, Huang MR, Lumbsch HT, Chun WJ. 2010 - Ascomycota has a faster evolutionary rate and higher species diversity than Basidiomycota. Science China Life Sciences. 53, 1163-1169.

Wignall PB, Kozur H, Hallam A. 1996 - The timing of palaeoenvironmental changes at the PermoTriassic (P/Tr) boundary using conodont biostratigraphy. Historical Biology 12, 39-62.

Zhang N, Castlebury LA, Miller AN, Huhndorf SM et al. 2006 - An overview of the systematics of the Sordariomycetes based on four-gene phylogeny. Mycologia 98, 1076-1087.

Zhaxybayeva O, Gogarten JP. 2002 - Bootstrap, Bayesian probability and maximum likelihood mapping: exploring new tools for comparative genome analyses. BMC Genomics 3, 1. 